\title{
Predecessors' Attitude toward Conflict Predictor of Family Business Sustainability
}

\author{
Linda Salim \\ Universitas Ciputra, Indonesia \\ salim.linda@gmail.com \\ Mohd. Noor Shariff \\ University Utara Malaysia \\ mdnoor@uum.edu.my \\ Darwina Ahmad Arshad \\ University Utara Malaysia \\ darwina@uum.edu.my
}

\begin{abstract}
Using qualitative interviews to understand the mindset of family business leaders in succession, this study proposes that attitude toward conflict is an important decision making element. A collective case studies uncover how attitude toward conflict predicts decision making during succession and influence optimism on the future of the firms. Findings of the study suggest that predecessors who welcome conflicts as a part of family firms take a more relaxed attitude toward succession, with a wider talent pool. This group are also more egalitarian in strategic decision making and optimistic toward the future of the firms. Predecessors who avoid conflict have smaller talent pool, making decisions to nominate few for the position. They is cautious, making decisions for the successors, and are pessimistic about the future of the firms. Contributions from this study are threefold. First, we introduce the use of attitude toward conflict to measure predecessors' behaviors during succession. Second, through identification of attitude toward conflict, we contribute to the literature by predicting predecessors' optimisms toward the future of the firms in the hands of the next generations. Third, this study contributes another dimension to reciprocal nepotism through discovery that family businesses upholding reciprocal nepotism behave differently.
\end{abstract}

Keywords: Family Business, Conflict, Family Business Succession, Attitude towards Conflict, Succession

\section{Introduction}

In her book on the history of family business, Colli (2003) pointed out that family business is arguably one of the oldest form of business institutions. This may give the impression that family firms have discovered the fountain of youth, unlocking the secret of corporate sustainability through intergenerational succession. Unfortunately, this is not the case. While Les Henokiens boasts memberships to 33 of the world's oldest family firms that has been in business for more than 200 years, Hay Group (2012) published a report that life expectancy of family firms in 10 Asian countries has shrunken to 24 years, an equivalent of 1.5 generations, 
from 50-60 years, 2-3 generations, in 1990 (The Economist, 2004). Hay Group's (2012) finding is not one of its kind. A year before, Credit Suisse (2011) reported similar findings. These findings would not have been of any urgency, should family business be an isolated phenomenon, but the literature agrees that family firms make a vast majority of business institutions even in capitalist countries (Caspersz \& Thomas, 2013; Nordqvist \& Melin, 2010).

In the past, scholars have assumed that family business is a temporary form of business model that will grow into a full-fledged professional firm upon growth when it is too big for the family to handle (Fukuyama, 1995; Halls, 1988; Chandler, 1980). Les Henokiens, however, proved otherwise. Despite the fact that it does not say anything about size, Les Henokiens' global presence gives the impressions that the age-old members are more than small operations. In fact, giant companies such as India's Tata Group, French LVMH, and Walmart are all family firms. Looking at how large companies managed to stay family-controlled and owned while statistics insist upon the failure of some $70 \%$ family firms going to generation two leadership, it is investigating how family firms manage their succession process (Credit Suisse, 2011).

In general, this study answers the question of why some family firms go through succession processes seamlessly while some never manage to complete theirs. Specifically, the authors addresses the following research questions: (a) How does predecessor's attitude toward conflict influence their approach to succession? and (b) How does attitude toward conflict predict predecessor's optimism toward the future of the firms under leadership of the successor? While there are many elements at play in the family business succession process, the literature maintains that succession does not happen until family business leaders, from this point on will be referred to, interchangeably, as predecessors, are willing to give the position of power to the successors (Michael-Tsabari \& Weiss, 2013). In fact, Hatak and Roessl (2013) added that many family business leaders, driven by fears and uncertainty, lingered past their tenure and refuse to leave. By no mean does this study aim to put the blame on the side of predecessors when succession does not happen. Nevertheless, the literature shows that until succession process is completed and successors rise to the position of de facto power, family business leaders are the key to the outcome of succession process (Blumentritt, Matthews, \& Marchisio, 2013).

Contributions of this study are threefold. First, we introduce the use of attitude toward conflict to measure predecessors' behaviors regarding succession. Attitudes toward conflict are identified as predecessors who treat conflicts as a natural part of business and predecessors who practice conflict avoidance. While conflict is a significant issue in family business, attitude toward conflict has never been measured.

Second, through identification of attitude toward conflict, we contribute to the literature by predicting predecessors' optimisms toward the future of the firms in the hands of the next generations, which in turn, commands how much contributions they allow successors to make in strategic planning.

Third, this article contributes another layer to the notion of reciprocal nepotism in family business. Jaskiewicz, Uhlenbruck, Balkin, and Reay (2013) proposed that family firms that have successfully survive through generations practice reciprocal nepotism. This study added another layer through discovery that all 
participants practice reciprocal nepotism, and yet, some of them are more cautious about the future of the firms due to their attitude toward conflict. This study suggests that family businesses with prevailing reciprocal nepotism goes through tough times during succession when the predecessors prefer to avoid conflict.

This article is structures as follows, for the rest of the paper, following this introduction, literature review of family business succession and related aspects such as conflict and communication is provided to synchronize the context of family business studied in this research paper. Research methodology will be laid out in detail afterwards, followed with findings, as well as discussions and recommendations.

\section{Literature review}

\subsection{Family Business}

Putting family business into one category can be misleading because of the variety of the business model. While it shares the quality of putting family members side by side in the workplace and intention to be passed down through generations, family business is very vibrant and diverse, including firms of many shapes and sizes, in every industry (Stewart \& Hitt, 2012; Chrisman, Chua, Pearson, \& Barnett, 2010).

\subsection{Family Business Succession}

Succession in family business has often been the spotlight of the field. While it no longer is one of the main researched topic, it remains one of the main research interests because why some family businesses are sustainable and some are not remains a mystery. Similar to the difficulty of defining family business, succession is hard to unwrap because of definitional discrepancy. We can study the same level of executive, through distributions of questionnaires to managing directors or interviews of chief marketing officers. In family business, the leader may hold different functions in their firms (Stewart \& Hitt, 2012; Chrisman, Chua, Pearson, \& Barnett, 2010). The only sure thing about them is that they hold a decision making position in both the family and the business. Therefore, in family business, it's important to understand the family before the business (James, Jennings, \& Breitkreuz, 2012, Chrisman, Kellermanns, Chan, \& Liano, 2010).

In the past, the dissolve of family businesses is often blamed on the management incompetence, which is an easy target, considering the fact that many startups became accidental family business through the exploitation of family capital when they could not afford to hire staff. In fact, as recently as 1995, worldrenown economist Francis Fukuyama, in his book 'Trust', wrote that low trust cultures such as Asian and Latin American countries do business through references, resulting in economies dominated by family businesses that develop in slower speed, in comparison to high trust, Western cultures. This, according to Fukuyama, is a drawback in the economy caused by the limited talent pool when hiring for family businesses. Stewart and Hitt (2012), however, countered the claim that hiring process in family firms are much simpler because the employers know the skills and qualifications of the potential employees. 
On the other hand, however, family firms' inability to structure a proper operational management was proven untrue when a study by Lam (2011) discovered that family members often disagree during succession process because of conflicting roles at home and at work. Lam (2011) added that skillful nonfamily employees can even step up to the plate and takeover operational issues while the family is dealing with succession. Stewart and Hitt (2012) suggested the middle ground, which professionalization is done in the form of leveraging the skills of family members

\subsection{Reciprocal nepotism}

Discussion on family business is ridiculous without nepotism. After all, a family business without nepotism is a mere business consisting of blood-related employees, which is common in developing nations such as Indonesia, as is an entrepreneurial startup utilizing family capital to staff the operation when the firm cannot afford to hire proper employees. Nevertheless, skepticisms surrounding family business as a viable business model often revolve around the narrow talent pool from which successors are nominated from, such that a search on Family Business Review resulted in exactly four articles with the word 'nepotism' on the titles, showing that even in the family business field, the word is preferably avoided.

A search of articles with the word 'nepotism' on the titles in Family Business Review results in a total of 4 articles since its first issue in 1988, one of which is a book review, leaving us with 3 articles mentioning nepotism in family business. The oldest article was not available during search, so rely on the latter two for references. This study adopt the notion of reciprocal nepotism, proposed by Jaskiewicz, Uhlenbruck, Balkin, and Reay (2013). While the notion was not empirically tested, the idea was proven in this study, that privileges such as primogeniture do not prevail in succession. Comparing family firm CEO to their nonfamily counterparts, Salvato, Minichilli, and Piccarreta (2012) agreed with the notion of reciprocal nepotism, reporting that CEO of family firms, while they are family members, are appointed for their qualifications. They also take as much time rising up to the rank as nonfamily CEO does.

\subsection{Decision making}

Among others, there are 3 studies about family business decision making that are very important to this study. In the beginning, family firms need to decide on utilization of family capitals. Some firms prefer to leave family capitals, such as family human capitals out of the firms while others use family financial capital to fund the firm (Sorenson \& Bierman, 2009).

Another important decision making associated with family business is which logic to use. Jaskiewicz, Heinrichs, Rau, and Reay (2015) pointed out the two major logics at play, family and commercial logics. For family firms to successfully cruise competitively, they have to use the two logics interchangeably. Taking the wrong logic on the wrong issue may cause them the firm.

The last part of decision making issues debated in family business is whether or not it is worth sacrificing family for work-related benefit. The literature was discussing about Chinese children of Chinese takeout places in the UK who risk discrimination when helping parents serve at the businesses (Jennings, Breitkreuz, \& James, 2013). 


\subsection{Conflict}

Conflict is not a new issue in family firms. Literature suggested family business succession is conflict-laden because it often involves intense emotions of actors involved in the process (Lam, 2011). Search of Family Business Review articles with the word 'conflict' in their titles result in a total of 13 articles, none of which talk about attitude toward conflict.

Despite suggesting that lack of communication can jeopardize succession process in family firms, Blumentritt, Mathews, and Marchisio (2013) noted that conflict is the source of failure in family business.

\section{Research Method}

Due to the basic fact that family business is a complicated subject involving multiple actors in different settings, at home and at work, family business succession is best studied qualitatively (Dawson and Hjorth, 2012). Because of the nature of the research objective, this study is designed as a qualitative collective case study, in which participants provide data through qualitative interviews that will then be processed through multiple layers of manual coding.

\subsection{Research setting}

Participants are taken from the seconds largest city in Indonesia, which is also the industrial hub for the eastern of the country, Surabaya. The place is chosen because two of the researchers are natives to Surabaya, bringing down the cultural gap and allowing the interpretation of the interview to the context of the local culture. Conducting the research in Surabaya also means that interviews are done in the mix of languages most comfortable for the participants, which may include one or more of the following, Surabaya-style Indonesian, Javanese, Mandarin, and Hokkien. Most people in Surabaya are either native to East Java or migrants from the outer islands such as Sumatera and Kalimantan who have successfully built communities of people from the same area.

The two largest groups inhabiting Surabaya are Javanese natives and ethnic Chinese who have been born and bred in Surabaya or its surrounding areas. There are also sizable Arabs and Indians who have been in the city for generations. The latter groups, however, are excluded from the samples due to the fact that they are either assimilated to the locals or behave more like their native origins. Many Arab families have married the locals and adopted local cultures, while Indian families often move back and forth between India and Indonesia.

The issue to understand participants colloquially is very important considering the fact that, while welcoming to newcomers, the people of Surabaya are more comfortable talking to locals who have similar backgrounds, in the mix of language that is unique to the region and their ethnic backgrounds.

In Surabaya, it is common for middle and upper class families to run businesses intended to be passed through generations. Taking over parents' businesses is so common in the city that it is a disgrace to the family when a child applies for a job. The participants are parents to grownup children between the ages of 18 and 53. 


\subsection{Research method}

A collective case study is the method of choice for this study to allow more robust cross-case analysis based on theme identification (Creswell, 2011). The two research questions are interconnected to one another. Conflict is a sensitive issue in Asia where the collective culture upholds agreement and age hierarchy. Therefore, asking straight forward about participants' attitude toward conflict was not a wise method of choice. To obtain the sought data, qualitative interviews were conducted where participants are asked about their succession process and changes that occurred when the children start getting involved in the firms.

\subsection{Data collection}

Participants of this study are selected based on the qualifications that they all are family business leaders in the midst or nearing succession, with next generation talent pools limited to their children. In one particular case, potential successors include two nephews from predecessor's shareholding sibling. The inclusion of the participants with more than his children as potential successors is purposive, to show the contrast of attitude toward conflict and conflict-handling.

Participants are chosen purposively from the first author's professional network. Careful considerations were taken into account to make sure personal opinions and biases are not interfering with data collection. Several qualified participants had to be scratched from the list due to the author's presumptions of them. Prevailing sampling methods are purposive and partial snowballing. Snowballed participants also undergo vetting to maximize demographic variety.

Data collection activity produced 7 robust interviews from 7 participants ranging from the age of 53 to 71. Participants' children range from 18 to 53. The broad range of age is meant to eliminate bias related to generational characteristics. Participants are owners of family firms in retail, manufacturing, and services industries, each with annual revenue of Rp. 50 million or more. The threshold is set because of Indonesia Law No. 20 Year 2008 about UMKM, which is Indonesian government regulation regarding the size of SME. Businesses with annual revenue under $\mathrm{Rp} 50$ million are considered micro, small or medium enterprise, which would skew the result because owners of small and medium businesses prefer to provide financial and human capital for their children to form start-ups of similar industries.

\subsection{Data analysis}

Recordings from the interviews were mind-mapped to reveal keywords and connections among keywords. The same protocol was done with the transcripts to increase validity, which was then compiled into one list of keywords. The final list of keywords was run against field notes containing observation notes of facial expressions, body languages, signs of discomfort and unease of the direction taken in the conversation, and changes in the tone of voice to increase reliability of the data. The list was later reduced until they revealed the main themes.

Transcripts from the interviews were also run through the Attitude Toward Conflict Scale to develop patterns of decision making (Bresnahan, Donohue, Shearman, and Guan, 2009). While the word 'conflict' is included in the research protocol, overall analysis is needed to test validity of the claim. 


\section{Result and Discussion}

Focusing on how predecessors' attitude toward conflict influences their approach to succession and their optimisms on the future of the firms, we divide the attitude toward conflict consistent to Bresnahan, Donohue, Shearman, and Guan's (2009). One one end, we found predecessors who perceive conflicts as a natural part of family firms, and on the other, we also collected data from those who are willing to avoid sibling and parental conflicts (Table).

\subsection{Predecessors who perceive conflicts as natural part of business}

Participants who perceive conflicts as part of business are naturally more open toward conflict, which is one of their valuable family capital. They believe that family remains whether or not the business survives. The attitude toward family also influences their talent pool. Not only do they welcome all children to join the companies, many also hire family employees in strategic positions, although they usually are not nominated as successors.

"I always welcome family who needs a job in the company. Some of them misused my trust. About years ago, my son in law, married to my second daughter, was cheated by his friend in Singapore. I had to absorb the loss, but what can I do? This is my business and they are my family. Now that son in law has passed away of heart attack, so I am glad we did not end on a bad note."

"Then, two years ago, my grandson in law did the same thing. I forgave him, but I did remind him not to do that again. I had to pay for the loss. At the end of the day, I am debt free, so I think this is the right thing to do for family"

(Participant E, generation 1).

"I was not wanted in the business, since my mother was the third wife. Surprisingly, when my father passed away, my stepmother (my father's first wife) asked me to buy out my stepbrother and stepsister so I have the right to run the company."

"I did what my stepmother asked as a gift (hibah) to my stepsiblings. By law, they were still co-owners. My legal advisor warned me against future problems but I trust my family."

(Participant F, generation 2).

On top of putting family first, this group does not believe in conflict that starts at home. Instead, good communication and solving disagreements early are key to harmonious workplace.

"We all grew up together, so we adhere to the same culture. If one of the spouses are, for example, Australian, and does not like to hang out with the family, it will 
lead to problem, but we all come from the same root. I do not believe any conflict could start at home."

"We have to keep things honest, even with my siblings who are not operationally involved. If they do not understand my decisions, especially regarding money, they will start getting suspicious. If it goes on for a long time, that will blow up into a divisive conflict."

"That was how my uncle and father split up. My uncle was a traditional Chinese trader, very good at saving money. My uncle did not like that my father kept using the corporate fund and my father was not happy because he made significant contribution. It went on and the siblings were divided into 2 blocs."

"I do not want that to happen to us, so I always keep everything communicated. When I talk to my nephews, I explain why I make the decisions. It takes time and not as efficient as talking to my staff but it is necessary. They need to bridge the communication, should their mother (my sister) asks about work."

(Participant A, generation 3).

Participants do not simply say that problems need to be extinguished early, they take it so seriously that one participant make it his business that disagreement are verbally settled and all parties agree that the case is closed. Many of them learn from past experience that no conflict is worth splitting up the family. This is apparent in Participant $\mathrm{F}$ who started in the family firm as the underdog.

"I have never seen a large conflict yet, but when my sons have problems with each other or their cousin, I will help them solve the problems openly. Last time, my son did something wrong that offended my brother. I told him to apologize and admit he was wrong."

(Participant F, generation 2).

Similar claim was made by Participant $\mathrm{F}$ who hires his brother as director of operation. He added that the key to a successful, conflict-free operation is not to be too tight on money, both to family and employees.

"I give all the commissions from vendors to my employees. They all get a share. Because of the stigma associated with working around funerals and the dead, many employees have been with me for generations. I never have argument with my brother." 
"He has been my managing director for the past 20 years, and we get along fine. His being with the company allows me to do social works that is related to my business. Most importantly, do not hold your money too tightly, then everything should be fine."

(Participant F, generation 7).

While the ultimate goal of both groups are the same, which is to retain control of the company within the family, predecessors in this group are well-aware that succession is a collective process where they have no complete control of.

"My children are informed that they are expected to support the company as I and my uncle did, but in the back of my head, I know that I have to appoint one of my managers to replace me if no one is capable or interested."

(Participant A, generation 3).

Because of the agreement on the importance of family supports and participations, this group tends to involve family members more in strategic decision making. The behaviour is most obvious in mapping out strategic decisions and next generation involvement.

"My daughter likes fashion. When she was in high school, I started trying to influence her decisions. I told her that fashion is a tough industry. She has to start from scratch with no guarantee of survival. Competition is fierce."

"Funeral services industry is much less competitive, because we already have the most market share in the business. There is a buffer, she will start at a safe position. Life will be comfortable."

(Participant F, generation 7).

When asked if his daughter bought into the argument, he explained what he really did:

"I asked my daughter if she would rather work really hard on something with no guarantee of success or on something relatively easy with high chance of survival. She picked the first choice, so I suggested she took funeral management. She did not come to work for me for another 16 years after graduation."

"But, really, I had it comfortable since the beginning, so I genuinely wanted to give her something for her future, even if she never works for me. Funeral management is a pretty undesirable field. Once she graduated, she would find a job easily. The industry is pretty unwanted, so anywhere she goes, it is pretty easy to compete." 
(Participant F, generation 7).

Overall, observation on this group suggests that the have more flexibility toward how business is run, including the shape of corporate goals. The ambition of keeping management control remains but realistically, these participants agree that they cannot force their offspring to have the same aspiration as they do.

\subsubsection{Predecessor who prefer to avoid conflicts}

Participants who show their preference to avoid conflicts are also passionately putting their families on the place of importance. It is upon this priority that they choose to separate one offspring from the other, to keep siblings from competition that may lead to the dissolve of the firms. The difference between this group and the previous one is their unit definition of family. The previous group looks at the family in its entirety, whereas this group looks at family as the next generation, the offspring, the future of the firm.

"My oldest and youngest are pretty similar, they can understand each other, and are equally skilful. If I put them together in the firm, they will have frequent conflicts, it is undesirable for the children to have disagreements, especially once we pass away."

(Participant $\mathrm{C}$, generation 1).

The attitude to avoid conflict is clearly shown upon questions on what they would do, should family members other than children intend to join the firms, such as children in law or nieces and nephews. One participant very sternly explain that his firm has enough leadership with his youngest son in place. He welcomes family members and relatives being involved with the firms as resellers but the company itself is reserved for his son (Participant $\mathrm{B}$, generation 1).

Both participants who show preference to keep conflicts at bay noted that their children's involvement in the business was their own initiatives. However, this group suggests that for the firm is best following the tracks they have planned before children's involvement. This group is less flexible in strategic planning and goal setting, believing it is best for successors to continue the existing plans.

"I usually do the initial approach. Once the deal is agreed upon, I delegate it to my son. Once he manages to achieve the goals I have set, he can plan the future, but as long as I remain, I give him the track to follow."

(Participant $\mathrm{C}$, generation 1).

When asked about the future of the firms, however, participants on this group are not as firm as their attitude on goal setting. They both admitted they were not. Participant B kept repeating his doubt when he questioned whether or not his is the right respond, as if he was being graded. Furthermore, there has been uncertainty when it comes to the other siblings. Participant $C$ who has one son in 
the family firm and two daughters working elsewhere asked the interviewer what they should do with the daughters:

"We have not think about shares for our daughters. Do other families give shares to daughters? Uhh...we honestly have not thought about it. We do not know what to do."

(Participant $\mathrm{C}$, generation 1).

As a whole, while this group is firm in their goal setting and less tolerant to changes as the children come to work in the family firms, they tend to be nervous about the future of the family businesses and are doubtful of their own decisions. At the same time, it is worth noting that reciprocal nepotism prevails here. Children chosen to succeed the parents are handpicked for their skills, and not for their entitlement.

\subsubsection{Anticipation for retirement}

In the interview protocol, there is a code that makes the mention of the word 'retirement' a must, just like it was the word 'conflict'. The authors anticipated participants to feel uneasy about the question, understanding the social stigma associated with the word in the particular culture. It is intentionally done to catch their reaction on both the question of their retirement itself and their feelings about the thought of leaving the firms completely in the hands of successors.

Data, however, suggests that attitude toward conflict has less to do with anticipation for retirement. Instead, participants' lifestyle is more relevant to the issue. For example, Participant A who is a self-admitting fan of conflict in the workplace informed the interviewer that he has joined his friends in a shrimping startup to prepare for the time when the children are able to handle the business on their own. Participant $C$ from the conflict avoidance group shared his dream of operating a phinisi boat for hire, leading groups of tourists on their fishing and diving trips.

It is easy to assume that family businesses that view conflicts as part of the business has higher chance of survival in the long run. Nevertheless, attitude is a constant that seldom change throughout one's lifetime (Azjen, 1991). Family business leaders who prefer to avoid conflicts have their own merits. From the business standpoint, leaders who welcome conflict creates a competitive environment where each idea is challenged for the best to prevail. Nevertheless, this can backfire if discussions take too long to conclude, resulting in too many cooks in the kitchen. This model is also dangerous should the predecessor perish before the leadership is handed over to the successor. Without their parent as a referee, the leadership can head south if all potential successors think of themselves as more capable than their siblings.

Conflict avoidance group encounters negative emotional issues when other offspring feel left out of the talent pool, but this is a lesser problem compared to what may happen if the successor feel so indebted for the parents for putting $\mathrm{him} / \mathrm{her}$ in the position of power and too afraid to voice personal opinion. In 
addition, the successor, while being the most capable, may not aspire to the same goals as the predecessor.

On the other hand, successor's awareness of parental expectation creates a strong stewardship that will ensure successor's effort in keeping the survival of the firm. Another strength of conflict avoidance group, due to its less flexible goal setting strategy, the firm can focus on the agenda, taking less time to adjust to new goals.

\section{Conclusion and Implications}

This study is important in understanding the missing link that determines family business survival through succession. Succession is the period where conflict is rampant, and inability to deal with the intensity of the conflicts and transition may lead to larger issues risking the survival of the family business. Succession is more emotional than strategic that many decisions are driven by fear of uncertainty (Lam, 2011). Ability to understand that attitude toward conflict, in and of itself, can predict a lot of behaviors open doors for future researches in helping predecessors keep looking ahead and successors to focus on firm survival.

Part of family business field is driven by culture that studying the business without understanding of the family leads to the wrong conclusion (James, Jennings, \& Breitkreuz, 2012), this study can benefit from more samples from other cultures to see how cultural variations would change the patterns. It will also be interesting if future research is conducted longitudinally to see if there are temporal changes.

Family business issues deal with maturity and past experience, which may change the attitude of both predecessors and successors as they both go through time. Being a qualitative study, this study lacks the ability to measure the intervals in between the two ends of being open to conflicts and avoiding conflicts. Future studies should also focus on measuring the conflict avoidance group's sensitivity toward conflict as this study has not yet gotten into what this group would do when they face conflict.

Contributions of this study are threefold. First, the use of attitude toward conflict as a predictor of predecessors' behaviors regarding succession assist with the diagnosis of what have gone wrong in the process. Conflict resolution is an important part of management. In family business, it is often dismissed as the less professional part of the business model. While it can be true that adding family into the business adds complication, not understanding family member's attitude toward conflict can make or break the family firm.

Second, identifying family business leaders' attitude toward conflict allows for prediction of predecessors' optimisms toward the future of the firms in the hands of the next generations. Level of optimism will be able to reveal how much freedom is given to the potential successors in strategic decision making. Practice in strategic decision making will increase successors' readiness to lead the family firm out of the shadow of their parents.

Third, this article adds another dimension to the notion of reciprocal nepotism in family business. Jaskiewicz, Uhlenbruck, Balkin, and Reay (2013) proposed that family firms that have successfully survive through generations practice reciprocal nepotism. This study stacks another dimension to reciprocal nepotism 
by measuring the amount of freedom given to successor in keeping the firm in operation. In other words, successors lacking the amount of freedom to do their best will not be able to act upon their competence. 
Table: Predecessors' attitude toward conflict

\begin{tabular}{|l|l|l|}
\hline & $\begin{array}{l}\text { Conflict as a } \\
\text { natural part of } \\
\text { business }\end{array}$ & Conflict avoidance \\
\hline $\begin{array}{l}\text { Intention for } \\
\text { succession }\end{array}$ & Plan A & Sole plan \\
\hline Talent pool & $\begin{array}{l}\text { Unlimited, all next } \\
\text { generation }\end{array}$ & $\begin{array}{l}\text { Select few, others kept } \\
\text { away from operation }\end{array}$ \\
\hline Decision making & $\begin{array}{l}\text { Egalitarian or } \\
\text { consultative }\end{array}$ & $\begin{array}{l}\text { Pre-drafted, predecessor- } \\
\text { controlled }\end{array}$ \\
\hline $\begin{array}{l}\text { Attitude toward } \\
\text { the family firms' } \\
\text { future }\end{array}$ & $\begin{array}{l}\text { Relaxed, successor is } \\
\text { well- equipped }\end{array}$ & $\begin{array}{l}\text { Nervous, hoping for the } \\
\text { best }\end{array}$ \\
\hline $\begin{array}{l}\text { Anticipation for } \\
\text { retirement }\end{array}$ & $\begin{array}{l}\text { Equally nervous of the } \\
\text { word 'retirement', } \\
\text { because of culture }\end{array}$ & \\
\hline $\begin{array}{l}\text { Reciprocal } \\
\text { nepotism }\end{array}$ & Applies in both groups \\
\hline
\end{tabular}




\section{References}

Blumentritt, T., Mathews, T. and Marchisio, G., (2013). Game theory and family business succession: An introduction. Family Business Review, 26(1),.5167.

Bresnahan, M.J., Donohue, W.A., Shearman, S.M. and Guan, X., (2009). Research note: Two measures of conflict orientation. Conflict Resolution Quarterly, 26(3), 365-379.

Caspersz, D. and Thomas, J., (2013). Developing Positivity to Manage. Family Business Review. Advance online publication. doi: 0894486513505641.

Chandler, A. D., 1980. Managerial Hierarchies, Harvard University Press.

Chrisman, J.J., Chua, J.H., Pearson, A.W. and Barnett, T., (2012). Family involvement, family influence, and family-centered non-economic goals in small firms. Entrepreneurship Theory and Practice, 36(2), 267-293.

Chrisman, J.J., Kellermanns, F.W., Chan, K.C. and Liano, K., (2010). Intellectual foundations of current research in family business: An identification and review of 25 influential articles. Family Business Review, 23(1), 9-26.

Colli, A., 2003. The history of family business, 1850-2000 (Vol. 47). Cambridge University Press.

Credit Suisse, (2011), Asian family businesses in report 2011, Switzerland.

Creswell, J.W., 2012. Qualitative inquiry and research design: Choosing among five approaches. Sage publications.

Dawson, A. and Hjorth, D., (2012). Advancing family business research through narrative analysis. Family Business Review, 25(3), pp.339-355.

Economist 2004, 'The world's oldest companies: The business of survival', 16 December,http://www.economist.com/node/3490684>

Fukuyama, F., (1995). Trust: The social virtues and the creation of prosperity.

Hall, P. D., 1998. A historical overview of family firms in the United States. Family Business Review, 1(1),.51-68.

Hatak, I.R. and Roessl, D.,(2015). Relational competence-based knowledge transfer within intrafamily succession: An experimental study. Family Business Review, 28(1), 10-25.

Hay Group, 2012, Family business in Asia: Breaking the third-generation curse, Singapore.

James, A.E., Jennings, J.E. and Breitkreuz, R.S., (2012. Worlds apart? Rebridging the distance between family science and family business research. Family Business Review, 25(1), 87-108.

Jaskiewicz, P., Heinrichs, K., Rau, S.B. and Reay, T., (2016). To be or not to be: how family firms manage family and commercial logics in succession. Entrepreneurship Theory and Practice. Advance online publication. doi: 10.1111/etap.12146.

Jaskiewicz, P., Uhlenbruck, K., Balkin, D.B. and Reay, T., (2013). Is nepotism good or bad? Types of nepotism and implications for knowledge management. Family Business Review, 26(2), 121-139.

Jennings, J.E., Breitkreuz, R.S. and James, A.E., (2013). When family members are also business owners: Is entrepreneurship good for families?. Family Relations, 62(3), 472-489.

Lam, W., (2011). Dancing to two tunes: Multi-entity roles in the family business succession process. International Small Business Journal, 29(5), 508-533. 
Michael-Tsabari, N. and Weiss, D., 2015. Communication traps: Applying game theory to succession in family firms. Family Business Review, 28(1), pp.26-40.

Nordqvist, M. and Melin, L., (2010). The promise of the strategy as practice perspective for family business strategy research. Journal of Family Business Strategy, 1(1), 15-25.

Salvato, C., Minichilli, A. and Piccarreta, R., (2012). Faster route to the CEO suite: Nepotism or managerial proficiency?. Family Business Review, 25(2), 206-224.

Sorenson, R.L. and Bierman, L., (2009). Family capital, family business, and free enterprise. Family Business Review, 22(3), 193-195.

Stewart, A. and Hitt, M.A., (2012). Why can'ta family business be more like a nonfamily business? Modes of professionalization in family firms. Family Business Review, 25(1), 58-86. 